\title{
Increased Burden on Women and Male Out-migration : An Analysis of Khul Gad Micro Watershed of the Kumoun Himalaya
}

\author{
Suman Singh \\ Department of Geography, Banaras Hindu University, India \\ *Corresponding Author: sumansingh.bhu@gmail.com
}

\begin{abstract}
In recent decades, as a consequence of environmental degradation and poor resource management in the marginal hilly areas of Uttrakhand (India) forced the males of the region to out-migrate in search of better employment. Due to lack of off-farm activities in these hilly areas, the burden of livelihood directly falls upon the womenfolk, who are considered as a 'Milieu Managers'. This has been reflected in the increasing participation of women in the economy of the study area. The present paper focuses on the pattern of migration and its adverse impact of increasing workload on the women of the study area. The study uses primary data collected through household surveys in Khulgad watershed, Almora district of the Kumaun Himalaya, Uttrakhand (India). Therefore, the key objective of the study is to analyse the increasing work participation of women operating at different sub-systems, impact of environmental degradation and role of women in sustaining the traditional agro-ecosystem in Khul Gad micro-watershed of the Kumoun Himalaya.
\end{abstract}

Keywords Environmental Degradation, Male Out-migration, Watershed, Increasing Workload, Milieu Managers

\section{Introduction}

Uttarakhand is one of the states marked by large number of population residing in the hills of the rural areas. These hilly rural areas offer most tough working and living conditions for its inhabitants. The areas do not provide conducive terrains for the development of industries or other sources of employment generation. The absence of industries and other sources of income and employment generation in these areas have always hooked its inhabitants towards agriculture and allied activities (Kandari, 2013).

The marginal areas of the Central Himalayas are plagued with faulty development programmes whose biggest manifestations can be seen in the amount and intensity of out flux, rather than exodus of male members from the region (Singh, 2014; 2015). The basic reason being the absolute lack of off-farm practices and the infeasibility of agricultural pursuits in economic terms. The entire state of Uttarakhand has a considerable population residing in the rural hill environs, wherein the terrain offers the toughest working and living conditions. The area is not conducive for the development of any industrial landscape courtesy to the undulating topography and lack of market (Dyson 2008; 2014). Over the decades the population of these regions have been increasing at a steady pace has created an immense pressure on the land resources of the region and the poor carrying capacity of the region has triggered massive male out migration in search of better employment activities. The contribution of agriculture to the state's domestic product is about 22.4 per cent (Agricultural Statistical at a Glance, 2014).

The entire central Himalayas are known as a region supported by 'postal economy', as the working male members migrate to earn a better livelihood. Sociologically, this creates an imbalance which is often termed as the "missing gender" as all the work are left of the womenfolk of the region to perform. Despite the hardships, the women of the region have played significant roles in both the domestic and agricultural sectors and have also become the backbone of the region's economy. The present paper analyses the increasing work participation of women operating at different sub-systems, impact of environmental degradation and the role of women in sustaining the traditional agro-ecosystem in Khul Gad micro-watershed of the Kumoun Himalayas.

\section{Methodology}

The present paper has been based mainly on primary data but uses secondary data as well. The secondary data is 
collected from the Census of India, 2011 for Almora district, as the watershed, the study area is a part of this administrative unit. For the study, population characteristics like distribution, literacy rate, working population, occupational status from the census were retrieved. According to the Census of India, 2011, the study area contains 33 Census villages.

A detailed primary survey of the study area had been conducted and the samples were purposively drawn using stratified random sampling technique. For the collection of data, a structured schedule was developed for women respondents only. Primary data had been collected by conducting interviews with 552 women in eleven selected villages located within the watershed.

\section{Objectives of the Study}

1. To assess the purpose of migration

2. How the process of male out-migration increases the work burden of women on selected villages.

3. Analyse the work participation of the women of the migrant and non-migrant households.

\section{The Study Area}

The Khul Gad watershed is spread over $25 \mathrm{~km}$ west from the Almora town in the Hawalbagh development block of Almora District in the Kumaun Himalaya of the Uttarakhand state. Khul Gad is a tributary of the river Kosi, which joins the Western Ram Ganga in the plains of Uttar Pradesh. Its peculiar spatial location has been one of the negative factors in the matter of development planning. Even otherwise, the area has been greatly exposed to the natural processes of slope insatiability and soil-erosion. "The notable demographic feature of the surveyed villages, which is related to the migration phenomenon, is the seemingly progressive sex ratio" (Table 1). According to the Census, 2011, the total population of the watershed is 10,207 consisting of 4895 males and 5312 females, that is, the female accounts for 52.04 per cent of the total population. The females exceeded the male only in the age group 15-59 years, whereas the male outnumbered the females in $0-5$ years and 60 and above age groups. This corroborates with our observation that in all villages, the male members are either children or the aged, implying that the whole household responsibility, including caring for the children and the aged, lies on the women" (Singh, 2014: 56).

Table 1. Demographic Traits of Khul Gad Watershed, 2011

\begin{tabular}{|c|c|}
\hline Households & 2254 \\
\hline Population & 10207 \\
\hline Male & 4895 \\
\hline Female & 5312 \\
\hline Sex Ratio & 1085 \\
\hline Male Literacy & 55.93 \\
\hline Female Literacy & 44.07 \\
\hline
\end{tabular}

Source: Census 2011
The land use (Table 2) of the region clearly depicts that the area under the forest cover in the village jurisdiction is nil while the maximum area of the villages lie under the other uncultivable land and uncultivable wasteland, which too remain generally barren but covered by uneconomic scrubs and grasses. The net sown area also lies on the steep slopes without contour bunding and those by the river tracts are small plots to be intensively cultivated.

Table 2. Land-use of Khul Gad Watershed, 2013

\begin{tabular}{|c|c|}
\hline Indicators & Area in Hectare \\
\hline Total Area & 2262.03 \\
\hline Area not Available for Cultivation & 313.95 \\
\hline Other Uncultivable Area & 1038.84 \\
\hline Net Sown Area & 909.24 \\
\hline
\end{tabular}

Source: Field Survey, 2013-14

The cropping pattern and the yields significantly vary from one village to another within the watershed depending upon the location of the villages/fields on the slopes. The soil and moisture are relatively more suitable in the valley villages and in north south portion of the slope. At the bottom of the slopes, farmers have cultivated some irrigated fields wherein Gul, Gads and Gaderas are the main sources of irrigation. Millets occupy maximum portion of the cultivated field along with wheat. The main crops cultivated in the watershed are wheat, mandua, jhangora, maize, pulses and vegetables. Agriculture in the region is basically done for self-provisioning. Commercialization of agriculture in the region seems impossible due lack of irrigation and other infrastructural setups, which invariably leads to low yield. The entire watershed experiences massive male out migration in search of jobs, as there is no off farm activity in the region, especially in Nanital, so womenfolk are in charge of the entire agricultural pursuit (Singh, 2014). Therefore, the wage labour and income from services forms the major sources of income in the Khul Gad watershed.

The main source of fuel woods is of course the protected/ reserved forests, which plays a crucial role in meeting the household demands. Villages lying by the roadside have a lesser dependency upon the fuel wood as they have access to LPG (Liquid Petroleum Gas) but its price increases away from the main contact road. The Khul Gad watershed also experiences acute water shortage, despite good monsoonal rains, the Gul, Gads and Gaderas of the region dry up especially during the summer season, which leads to conflicts upon the quota of water used by households for drinking and irrigation purposes. Land degradation is a prominent feature of the region and cultivation on slopes steeper than normal without any contour bunding or agro forestry has become the trademark.

The common property resources are diminishing rapidly and people are increasingly becoming dependent upon the reserved forests for their basic needs. As stated above, lack of off farm activities has induced a massive male out 
migration. This creates a vicious cycle of poverty and satiating basic needs, which cries out loud for answers to the road of sustainable development. This has to come from public participation otherwise like many other watersheds the story would not be successful as has been the case throughout the country over the years. Unless and until the stakeholders are involved into the process of formulation, implementation and monitoring the entire endeavour would be futile.

\section{Impact of Out-migration on Women}

The area is characterized by immense lack of off farm practices and has witnessed massive single male outmigration over the decades. Once the working age group males go outside in search of job, the entire domestic and agricultural burden falls upon the left behind womenfolk. The following table shows a clear picture of the amount of out fluxes from the Khul Gad micro watershed.

Table 3. Out-migration Status of sampled villages, Khul Gad Watershed

\begin{tabular}{|c|c|c|c|c|c|}
\hline Villages & $\begin{array}{c}\text { Total no. of sample } \\
\text { HH } \\
\end{array}$ & No. of Migrant & $\begin{array}{c}\% \text { of Migrant from } \\
\text { sample HH }\end{array}$ & No. of Non-Migrant & $\begin{array}{r}\% \text { of Non } \\
\text { Migrant }\end{array}$ \\
\hline Batgal Rautela & 25 & 30 & 3.72 & 55 & 4.11 \\
\hline Salla Rautela & 51 & 73 & 9.05 & 124 & 9.27 \\
\hline Syahi Devi & 14 & 41 & 5.08 & 55 & 4.11 \\
\hline Naula & 35 & 52 & 6.45 & 87 & 6.5 \\
\hline Bimola & 110 & 177 & 21.96 & 287 & 21.46 \\
\hline Dhamas & 135 & 145 & 17.99 & 280 & 20.94 \\
\hline Khunt & 55 & 80 & 9.92 & 135 & 10.07 \\
\hline Jyuli & 48 & 94 & 11.66 & 142 & 10.62 \\
\hline Kharkuna & 11 & 5 & 0.62 & 25 & 1.86 \\
\hline Deolikhan & 23 & 75 & 9.3 & 98 & 7.32 \\
\hline Bisra & 15 & 34 & 4.21 & 49 & 3.66 \\
\hline Total & 522 & 806 & 99.96 & 1337 & 99.92 \\
\hline
\end{tabular}

Source: Field survey 2013-2014

It is important to note here that the no. of non-migrants contains the womenfolk, children and aged populations. So, if we analyze objectively the dependent population besides the women of the region compose the non migrants.

Table no 4 shows the distribution of migrants on the basis of age and purpose of migration. The study further shows that majority of the migration from these regions have been due to the unavailability of employment opportunities in them. The table depicts that majority of the migrants who have migrated from these regions fall in the age group of 15 to 30 years, and also from the age group of 31 to 50 years. This clearly signifies that these sections of the population which constitutes the main workforce of any section of the community has moved away from these regions resulting in the loss of human resource, which negatively has an effect on the economic development of these regions, which are itself surrounded with the number of problems.

Table 4. Purpose of Male migration, Khul Gad Watershed

\begin{tabular}{|c|c|c|c|c|c|}
\hline Purpose of Male migration & $\begin{array}{c}0-15 \\
\text { Age group }\end{array}$ & $\begin{array}{c}15-32 \\
\text { Age group }\end{array}$ & $\begin{array}{c}32-50 \\
\text { Age group }\end{array}$ & Above 50 Age group & Total \\
\hline Occupation & -- & 432 & 212 & -- & 644 \\
\hline Education & 34 & 128 & -- & -- & 162 \\
\hline Total & 34 & 560 & 212 & 0 & 806 \\
\hline
\end{tabular}

Source: Field survey 2013-2014

\section{Women: Drudgery of Labour and Struggle}

Women of the study area like any other rural women of the central Himalayas share the responsibility of earning bread for the family with the male counterparts. Agriculture and animal husbandry for the basic mainstay of this endeavour as the male members out-migrate in search of better employment practices. The women of Khul Gad watershed carry almost all the agricultural operations starting from tilling to harvesting, whereupon the success or failure of agricultural production depends solely upon the contribution made by women folk. Besides the agricultural work, animal husbandry and domestic chores are entirely women's' burden too. A detailed analysis of the disposal of daily time and percentage distribution of work done by women of the study area has been presented in the following Table 5 . 
Table 5. Additional Workload on Women of Migrant households (distribution in percentage of additional work in different activities)

\begin{tabular}{|c|c|c|c|c|c|c|}
\hline Village & Agriculture & Animal Rearing & $\begin{array}{c}\text { Collection of } \\
\text { Water }\end{array}$ & $\begin{array}{c}\text { Collection of } \\
\text { Fodder \& Fuel } \\
\text { wood }\end{array}$ & $\begin{array}{c}\text { Household } \\
\text { Activities }\end{array}$ & Total \\
\hline Batgal Rautela & 25.00 & 9.52 & 10.02 & 22.12 & 33.34 & 100 \\
\hline Salla Rautela & 17.65 & 18.08 & 12.34 & 39.43 & 12.50 & 100 \\
\hline Syahi Devi & 35.29 & 17.65 & 10.76 & 20 & 25.53 & 100 \\
\hline Naula & 32.00 & 8.00 & 14.45 & 25.55 & 20.00 & 100 \\
\hline Bimola & 33.33 & 5.00 & 12.76 & 22.58 & 26.33 & 100 \\
\hline Dhamas & 25.00 & 5.04 & 13.08 & 22.88 & 34.00 & 100 \\
\hline Khunt & 28.58 & 14.09 & 10.45 & 21.35 & 25.53 & 100 \\
\hline Jyuli & 18.18 & 16.67 & 13.07 & 24.84 & 27.24 & 100 \\
\hline Deolikhan & 20.29 & 18.08 & 10.34 & 22.46 & 30.05 & 100 \\
\hline Bisra & 25.09 & 17.65 & 13.02 & 20.7 & 23.54 & 100 \\
\hline
\end{tabular}

Source: Computation based on Field Survey, 2013-2014

Different types of additional activities were reported by the respondents, which they performed in the absence of their male members who have migrated. Table 5: shows the main types of works, which lead to additional burden on the womenfolk of the migrant households. As a result of migration of male members, the first and foremost additional burden of work on women, related to agricultural operations. The male member does not perform any agricultural activities except for ploughing.

There is a common belief that only the men are supposed to plough the field. Where adult male members are not available in the households, the women have either to pay money for ploughing work or to give their own labour to others in exchange of ploughing operation. Household activities like childcare and care of the aged person is another additional activity in which the women have to devote relatively more time as compared to the past when there were no migrants from the family. Some of the respondents of migrant households reported that they have to perform the activities of marketing as additional work. The marketing activities consist of purchases of necessary domestic's items, agricultural inputs, medicines and books for the children and stationeries.

A fundamental inference of the Table above highlights the drudgery of the hill women, whereupon 'a woman' on an average devotes around 16 straight hours every day doing her job and compensating the work that was supposed to be done by the missing gender (the male member). This finding corroborates with many previous studies (Singh, 2015; Bhattacharyya et al., 2011; Bhattacharyya and Vauquline, 2013). It is important to note here that this 16 hours is an aggregate figure, the work done by womenfolk of the region varies from season to season (Bhattacharyya, 2009; 2013; Sarma, 2009). For example, in the summers, a woman has to travel less to collect fuel wood but has to travel more for collecting water and fodder. The household activities by far remain the same in the entire year. The author feels important to mention here that within the womenfolk too, there is a huge disparity; the computation presented in the Table above reflects on the workload of the daughter-in-laws/wives not the daughters. The daughters too have to share the workload but theirs' is considerably low.

The process of migration in the entire central Himalayan region is basically a male dominant affair, so is the case with the study area, Khul Gad. As the working male population out migrates, their work has to be compensated by the left behind womenfolk. Therefore, besides outdoor work, the domestic work too increases as more time is supposed to be spent upon child and aged members' care.

The analysis of data pertaining to the working pattern of respondents and work load on them (women) according to migrant and non migrant households has been made in Table 5. When we compare the per woman total hours of daily work in migrant household with the hours of daily work in non-migrant households, it is found that a woman in migrant households works about 17.14 hours (averagely) in a day. Where's in nonimmigrant households a women has to work about 15.70 hours (averagely) in a day. In other words, the present paper revealed that a woman in migrant household has to devote about 1.44 hours more time than the women of non-migrant household in day to day activities as a result of out- migration of male members. The burden of work on women in the case of migrant households in all the villages under study is relatively more than that of non- migrant households. However, there has been variation in the magnitude of workload. The work variation of women between migrant and non-migrant households was found in village Naula followed by village Bisra, Syahi Devi. The hours of work differentials of women in migrant and non-migrant households were recorded lowest in village Deolikhan followed by village Bagat Rautela, Salla Rautela. 
Table 6. Per women hours of daily work in migrant and non-migrant households

\begin{tabular}{|c|c|c|c|c|}
\hline & \multicolumn{2}{|c|}{ Migrant House Holds } & \multicolumn{2}{c|}{ Non migrant House Holds } \\
\hline Name of Village & No. Of respondents & $\begin{array}{c}\text { Per women total hours of } \\
\text { daily work }\end{array}$ & $\begin{array}{c}\text { No. of Respondents } \\
\text { work }\end{array}$ & \begin{tabular}{c} 
Per women tot hours of daily \\
\hline Batgal Rautela
\end{tabular} \\
\hline Salla Rautela & 57 & 15.38 & 20 & 14.73 \\
\hline Syahi Devi & 50 & 17.12 & 45 & 14.06 \\
\hline Naula & 48 & 17.05 & 30 & 13.8 \\
\hline Bimola & 60 & 17.64 & 50 & 17.02 \\
\hline Dhamas & 45 & 18.66 & 50 & 17.41 \\
\hline Khunt & 70 & 18 & 58 & 16.07 \\
\hline Jyuli & 43 & 17.35 & 35 & 16.52 \\
\hline Kharkuna & 44 & 18.63 & 40 & 16.25 \\
\hline Deolikhan & 35 & 17.05 & 30 & 15.73 \\
\hline Bisra & 25 & 14.62 & 20 & 14.25 \\
\hline Total/Average & $\mathbf{5 0 1}$ & 17.12 & 15 & $\mathbf{1 5 . 7 0}$ \\
\hline
\end{tabular}

Source: Computation based on Field Survey, 2013-2014

\section{Conclusions}

The process of development has no meaning, especially in the marginal hilly areas of the country, unless women are fully integrated in it. The status of women starts from the household where she takes birth grows and thus accordingly her outlook and perceptions are influenced. The work burden on females of the study area and their contribution to such work in rural areas of the hill region is very high and significant. Still the lack of economic and social independence marginalises her both domestically and socially. A woman has to take permission from the males for all the domestic and agricultural pursuit.

Gender equity emerges as a major variable in community related factors, which affects collective action by communities in decentralized governance. All across this Himalayan region, male outmigration has resulted in women being forced to perform the duties of the active labour force. Yet, their participation is not accounted for and even the government machinery labels them as marginal workers, their role in politics and governance is very low, with little or no involvement in decision making. Areas like the Himalayas, where conventional agricultural and industrial developments face severe constraints, there are still many obstacles impeding the inclusion and influence of different marginalized groups, especially women in politics and governance in mountain regions of India. (Agarwal, 1992, 2010)

Keeping in highest perspective the increased workforce participation of females in agriculture and low wage employment the government support becomes essential to such section of the population. The government support should focus on supporting the active female workforce through imparting skill development to get them involved in the higher paid work or to step up in entrepreneurship development. The government should further act on removing the barriers in the female's workforce participation, which largely constitutes of the health problems. The other major emphasis should be on the supportive programs for the development of agriculture activities as the women constitutes the major workforce involved in agriculture. The changing trend in the increase in the female work force participation is a positive sign of initialization of the women empowerment process. Thus, the role of the government and other development actors like social activities, NGO's and others should be to promote the involvement of women in the economic sphere. The increasing participation of women and greater gains from it will not only economically make them independent but will also help in a long way in the overall development of such regions (Kandari 2013)

Women in the Central Himalayas play an active role in the socio-economic life. The process of achieving gender equity is symbiotic with the process of political/social participation by the women in marginalised mountain regions. It is high time that not only the 'missing gender' but also the governments have to hear the voice of the hard working womenfolk of the region as they are not only the ultimate stakeholders but also the societal and environmental sounding boards of the Himalayan ecosystem.

\section{Acknowledgements}

I am very grateful to Dr. Rituparna Bhattacharyya for their appropriate and constructive suggestions. 


\section{REFERENCES}

Agarwal, Bina Gender and Green Governance: The Political Economy of Women's Presence Within and Beyond Community Forestry), OUP, 2010.

Agarwal, Bina. The Gender and Environment Debate: Lessons from India, Feminist Studies Minnesota, 1992.

Ansell, C. and A. Gash. "Collaborative Governance in Theory and Practice", Journal of Public Administration Research and Theory 18 (4): 543-571, 2007.

Berreman, G., Chipko: Non-violent direct action to save the Himalayas. South Asian Bulletin, 5(2), 8-13, 1985.

Bhattacharyya, R. and Vauquline, P. A Mirage or a Rural Life Line?: Analysing the Impact of Mahatma Gandhi Rural Employment Guarantee Act on Women Beneficiaries of Assam, Space and Culture, India, 1(1), 83-101, 2013.

Bhattacharyya, R. Are We Empowered? Stories of Young Indian Working Women, Saarbrücken, Germany: Lap Lambert Academic Publishing, 2013.

Bhattacharyya, R., Vauquline, P. and Singh, S. Towards a Socially Sustainable India: An Analysis of National Rural Employment Guarantee Scheme, 2006. In S.K. Singh, Raj Kumar, H.P. Mathur, N.B. Singh and V.K. Kumra (eds). Energy Resources, Alternative Search and Sustainable Development, New Delhi: Shree Publishers, 73-88, ISBN: 978-81-8329-395-2, 2011.

Bhattacharyya, R.. Examining the Changing Status and Role of Middle Class Assamese Women: Lessons from the Lives of University Students, PhD thesis, Newcastle University, UK, 2009.

Census of India 2011. Provisional Population Totals Uttarakhand, Office of the Director, Census, Uttarakhand, 2011.

Dyson, Jane. Harvesting Identities: Youth, Work, and Gender in the Indian Himalayas, Annals of the Association of American Geographers, 98:1, 160-179, DOI: 10.1080/00045600701734554, 2008 .

Dyson, Jane. Working Childhoods: Youth, Agency and the Environment in India. Cambridge, United Kingdom: Cambridge University Press, 2014.

Government of Uttarakhand, Report, Department of Panchayati Raj, 2009.

Guha, R., The Unquiet Woods: Ecological Change and Peasant Resistance in the Himalaya (Expanded ed.). Berkeley, CA: University of California Press. 2000

Guha, Ramchandra,. Unquiet Woods: Ecological Change and Peasant Resistance in the Himalayas, Oxford University Press, Delhi, 1989.

Joshi D. Joshi, D. Gender and Green Governance. Unpublished Award Winning Case Study, IIPA, New Delhi, 2011.
Kandari, Prashant, Migration Pattern and the increasing Participation of Females in the Economy of Hill Rural Areas: A Study of Pauri district in Uttarakhand, IOSR Journal Of Humanities And Social Science (IOSR-JHSS) Vol. 17(5) (Nov. Dec. 2013), pp.27-33, 2013

Kunwar, C. (Ed.). Emancipated Women-Folk of Uttarakhand. Dehradun: Himalayan Action Research Centre, 1997.

Mishra, A. \& Tripathi, S. Chipko movement: Uttarakhand women are bid to save forest wealth. New Delhi: Peoples Action/Gandhi Book House, 1978.

Pant S.D.. The Social Economy of the Himalayas, George Allen and Unwin, p. 216. (1935)

Pathak Shekhar. Uttarakhand Main SamajikAndolano ki Rooprekha, Pahar Pustika 3, Nainital, India, 1992.

Pathak ShekharKumaoni. Society Through the Ages, in K.S. Valdiya (ed.) Kumaon: Land and People, Gyanodaya Prakashan, pp. 99-102, 1986

Rawat, R. Women of Uttarakhand: On the Frontier of the Environmental Struggle. Ursus, 7(1), 8-13, 1996.

Routledge, P. The Chipko Movement, Terrains of Resistance: Nonviolent Social Movements and Contestation of Place in India. Westport, Conn.: Praeger, 1993.

Sarma, R. B. Feminist Political Economy. In Kitchin R, Thrift N (eds) International Encyclopedia of Human Geography, Oxford: Elsevier, Volume 4, 79-86, 2009.

Shiva, Vandana. Chipko: India's civilization response to the forest crisis. New Delhi: INTACH, 1986.

Shiva, Vandana. Staying Alive: Women, Ecology and Development. London: Zed Books, 1989.

Singh Suman Women, Environment and Sustainable Development: A Case Study of Khul Gad Micro Watershed of Kumoun Himalaya, Space and Culture, India 2014, 1:3 pp. 53-64, 2014.

Singh, S. B. Women as Milieu Managers in Integrated Watershed Management: Perspectives from the Hilly Areas of Uttarakhand, Journal Space and Culture, India, 2(4), 71-79, 2015.

Stoker, G., Designing Institutions for Governance in Complex Environments: Normative Rational Choice and Cultural Institutional Theories Explored and Contrasted. Manchester, UK: Economic and Social Research Council Fellowship Paper No 1, 2004

UNDP Gender Equity Indicators in UNHDR India, 2011, New Delhi, 2011.

Upadhyaya, D., The Participation of Women in Politics: A study with special reference to Kumaun. Unpublished Ph.D Thesis, Kumaun University,Nainital ,India, 2000. 